\title{
(Research Article) \\ Chaotic Algorithm for Solving Optimal Reactive Power Problem
}

\author{
Dr. Kanagasabai Lenin ${ }^{1 *}$ \\ ${ }^{\text {I*} P r o f e s s o r, ~ D e p a r t m e n t ~ o f ~ E E E, ~ P r a s a d ~ V . P o t l u r i ~ S i d d h a r t h a ~ I n s t i t u t e ~ o f ~ T e c h n o l o g y, ~ K a n u r u, ~ V i j a y a w a d a, ~ A n d h r a ~ P r a d e s h ~-520007, ~}$
}

\begin{abstract}
In this work Chaotic Krill Herd (CKH) algorithm is utilized to solve the optimal reactive power problem. Herd behaviour deeds of the Krill individuals are imitated to formulate the algorithm. Key task for the Krill movement is the least distance of each individual Krill from food to the maximum concentration of the herd. Based on the persuaded movement of other Krill's, foraging movement and substantial propagation the location of every krill in a time period is depended. Chaos theory and the logistic chaotic mapping are used in substantial propagation to improve the search ability of the proposed algorithm. Proposed Chaotic Krill Herd (CKH) algorithm has been validated in IEEE 57, 300 test systems. Real Power Loss is reduced considerably when compared to other standard algorithms.
\end{abstract}

\section{Keywords: Optimal Reactive Power, Transmission loss, optimization, Chaotic Krill Herd}

\section{Introduction}

In power system operation \& control, reactive power problem plays the key role in secure \& economic operation of the power system. Several conventional methods [1-6] used already for solving the problem. But many drawbacks have been found in the conventional methods and mainly difficulty in handling the inequality constraints. Last two decades many evolutionary algorithms [7-17]. In this work Chaotic Krill Herd algorithm is utilized to solve the optimal reactive power problem. Herd behaviour deeds of the Krill individuals are imitated to formulate the algorithm. Key task for the Krill movement is the least distance of each individual Krill from food to the maximum concentration of the herd. Based on the persuaded movement of other Krill's, foraging movement and substantial propagation the location of every krill in a time period is depended. The symphony of the krill herd after predation depends on many parameters. The herding of the krill individuals has two key goals: swelling of krill concentration, and accomplishment of food. Depth of grouping the krill (mounting concentration) and finding food (region of elevated food concentration) are used as objectives which ultimately direct the krill herd approximately the global minimum. In this process, an individual krill budge toward the most excellent solution when it explore for the uppermost concentration and food. Progression persuaded by other krill individuals by Foraging action and arbitrary propagation. Chaos theory and the logistic chaotic mapping are used in substantial propagation to improve the search

"Corresponding Author: e-mail: gklenin@gmail.com ISSN 2320-7590

(C) 2020 Darshan Institute of Engg. \& Tech., All rights reserved ability of the proposed algorithm. Proposed Chaotic Krill Herd (CKH) algorithm has been validated in IEEE 57, 300 test systems. Real Power Loss is reduced considerably when compared to other standard algorithms.

\section{Problem Formulation}

Main aim is to minimize the system real power loss \& given as,

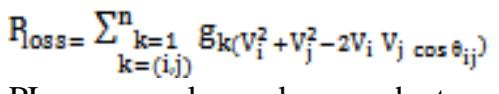

$\mathrm{PL}$ - power loss, gk - conductance of branch, $\mathrm{Vi}$ and $\mathrm{Vj}$ are voltages at buses i, j, Nbr - total number of transmission lines in power systems.

Voltage deviation magnitudes (VD) is,

$\operatorname{Min}(\mathrm{VD})=\sum_{\mathrm{k}=1}^{\mathrm{nl}}\left|\mathrm{V}_{\mathrm{k}}-1.00\right|$

Load flow equality constraints:

$P_{G i}-P_{D i}-V_{i} \sum_{j=1}^{n b} v_{j}\left[\begin{array}{cc}G_{i j} & \cos \theta_{i j} \\ +B_{i j} & \sin \theta_{i j}\end{array}\right]=0, i=1,2 \ldots \ldots n b$
$Q_{G i}-Q_{D i}-V_{i} \sum_{j=1}^{n b} v_{i j}\left[\begin{array}{cc}G_{i j} & \sin \theta_{i j} \\ +B_{i j} & \cos \theta_{i j}\end{array}\right]=0, i=1,2 \ldots \ldots n b$

active power of slack bus is symbolized by $\mathrm{PG}$ and reactive power of generators symbolized by QG

Inequality constraints are:

Upper and lower bounds on the bus voltage magnitudes (Vi) is given by:

$\mathrm{V}_{\mathrm{Gi}}^{\min } \leq \mathrm{V}_{\mathrm{Gi}} \leq \mathrm{V}_{\mathrm{Gi}}^{\max }, \mathrm{i} \in \mathrm{ng}$ 


$$
V_{\mathrm{Li}}^{\min } \leq \mathrm{V}_{\mathrm{Li}} \leq \mathrm{V}_{\mathrm{Li}}^{\max }{ }_{,} \mathrm{i} \in \mathrm{nl}
$$

Upper and lower bounds on the compensators $(\mathrm{Qc})$ is given by:

$Q_{C i}^{\min } \leq Q_{C i} \leq Q_{C i}^{\max }, i \in$ nc

$Q_{G i}^{\min } \leq Q_{G i} \leq Q_{G i}^{\max }{ }_{0} i \in \mathrm{ng}$

Upper and lower bounds on the transformers tap ratios (Ti) are given by:

$\mathrm{T}_{\mathrm{i}}^{\min } \leq \mathrm{T}_{\mathrm{i}} \leq \mathrm{T}_{\mathrm{i}}^{\max }{ }_{,} \mathrm{i} \in \mathrm{nt}$

$\mathrm{S}_{\mathrm{Li}}^{\min } \leq \mathrm{S}_{\mathrm{Li}}^{\max }{ }_{0} \mathrm{i} \in \mathrm{nl}$

\section{Krill herd algorithm}

Krill has capability of forming huge swarms. Systematic deeds of krill have been imitated to form the algorithm. The krill individuals try to preserve an elevated concentration and budge due to their shared effects [18]. Itinerary of motion persuade, $\alpha_{i}$, and is computed from the local swarm concentration (confined outcome), a target swarm concentration (attack outcome), and a repulsive swarm concentration (hideous outcome) .

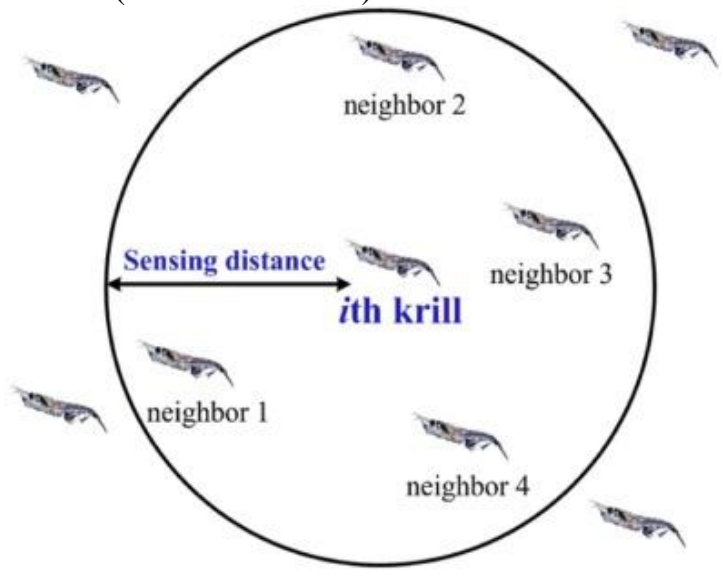

Figure 1. Krill position

Krill's individual movement can be defined as:

$P_{i}^{\text {new }}=P^{\max } \alpha_{i}+\omega_{n} P_{i}^{\text {old }}$

Where

$\alpha_{\mathrm{i}}=\alpha_{\mathrm{i}}^{\text {confined }}+\alpha_{\mathrm{i}}^{\text {attack }}$

$P_{i}^{\text {new }}$ - new movement of krill, $P^{\max }$ - maximum movement of krill, $\omega_{n}$-inertia weight, $\alpha_{i}^{\text {confined }}$ - effect provided by neighbours, $\alpha_{i}^{\text {attack }}$ - direction provided by best krill

Individual krill movement based on the outcome of the neighbours is defined by:

$\alpha_{i}^{\text {confined }}=\sum_{j=1}^{p p} \widehat{K}_{i j} \hat{Z}_{i j}$ $\hat{z}_{i, j}=\frac{z_{j}-z_{i}}{\left\|z_{j}-z_{i}\right\|+\varepsilon}$

$\widehat{K} H_{i, j}=\frac{K H_{i}-K H_{j}}{K H^{\text {poor }}-K H^{g 00 d}}$

$\hat{Z}_{i j j}$ - relative positions, $\widehat{K} H_{i, j}$ - fitness of the krill herd

Each krill individual sensing distance can be found for every iteration:

$D S_{a i}=\frac{1}{E N} \sum_{j=1}^{N}\left\|Z_{i}-Z_{j}\right\|$

$D S_{s, i}$ - sensing distance of the krill

Most excellent fitness of individual krill is taken into account by,

$\alpha_{\mathrm{i}}^{\text {attack }}=C F^{\text {good }} \widehat{K}_{\text {i good }} \hat{Z}_{\text {i good }}$

$C F^{g o o d}$ - effect of the coefficient of the krill

$C F^{\text {good }}$ is defined as:

$C F^{\text {good }}=2\left(\right.$ random $\left.+\frac{I}{I_{\operatorname{maximum}}}\right)$

For the ith krill individual the Foraging motion can be articulated by,

$F g_{\mathrm{i}}=v l_{f} \beta_{\mathrm{i}}+\omega_{f} F g_{\mathrm{i}}^{\text {old }}$

Where

$\beta_{\mathrm{i}}=\beta_{\mathrm{i}}^{\text {food }}+\beta_{\mathrm{i}}^{\text {good }}$

$v l_{f}$ - foraging speed, $\omega_{f}$ - inertia weight, $F g_{\mathrm{i}}$ - last foraging motion, $\beta_{i}^{\text {food }}$ - food attractive

For every iteration the centre of food is created by,

$Z^{f \circ 0 d}=\frac{\sum_{i=1}^{P} \frac{1}{K_{i}} Z_{i}}{\sum_{i=1}^{P} \frac{1}{K H_{i}}}$

for the ith krill individual food attraction is given as:

$\beta_{\mathrm{i}}^{\text {food }}=C F^{\text {food }} \widehat{K}_{i, f o o d} \hat{Z}_{i, f o o d}$

The food coefficient is defined by,

$C F^{\text {food }}=2\left(1-\frac{I}{I_{\operatorname{maximum}}}\right)$

Most excellent fitness of the ith krill individual is found by:

$\beta_{\mathrm{i}}^{\text {best }}=\widehat{K}_{\text {Higood }} \hat{Z}_{\text {iligood }}$

The physical dissemination, utmost dissemination speed is formulated as follows: 
$D S_{\mathrm{i}}=D S^{\text {maximum }} \delta$

On the basis of a geometrical annealing sketch out, it can be formulated as:

$D S_{\mathrm{i}}=D^{\operatorname{maximum}}\left(1-\frac{I}{I_{\operatorname{maximum}}}\right) \delta$

Position vector of a krill individual during the interval $\mathrm{t}$ to $\mathrm{t}+$ $\Delta t$ is given by,

$Z_{i}(t+\Delta t)=Z_{i}(t)+\Delta t \frac{d z_{i}}{d t}$

$\Delta t$ Entirely depends on the search space and it obtained from the following,

$\Delta t=C F_{t} \sum_{j=1}^{p V}\left(U B_{j}-L B_{j}\right)$

Genetic reproduction mechanisms are integrated into the Krill herd algorithm to improve the performance of the algorithm.

a. Crossover

$Z_{\mathrm{i}, m}= \begin{cases}Z_{r_{m} m} \text { random } \mathrm{i}_{\mathrm{i}, \mathrm{m}}<C r \\ Z_{\mathrm{i}_{m} m} \text { else }\end{cases}$

$C_{Y}=0.210 \widehat{K H}_{i, \text { best }}$

b. Mutation

$Z_{\mathrm{i}, m}=\left\{\begin{array}{c}Z_{g b e s, m}+\mu\left(Z_{p, m}-Z_{q m}\right) \text { random } m_{i, m}<M u \\ Z_{i, m} \quad \text { else }\end{array}\right.$

$M u=0.0475 / \widehat{K}_{\text {i, best }}$

a. Initialization of population.

b. Fitness assessment of each krill individual based on its location.

c. Motion calculation:

Motion induced by the attendance of other individuals,

Foraging movement

Physical propagation

d. Applying the genetic operators

e. Updating krill individual location in the search space.

f. until the stop criteria is reached; Replicate: go to step fitness evaluation

g. End

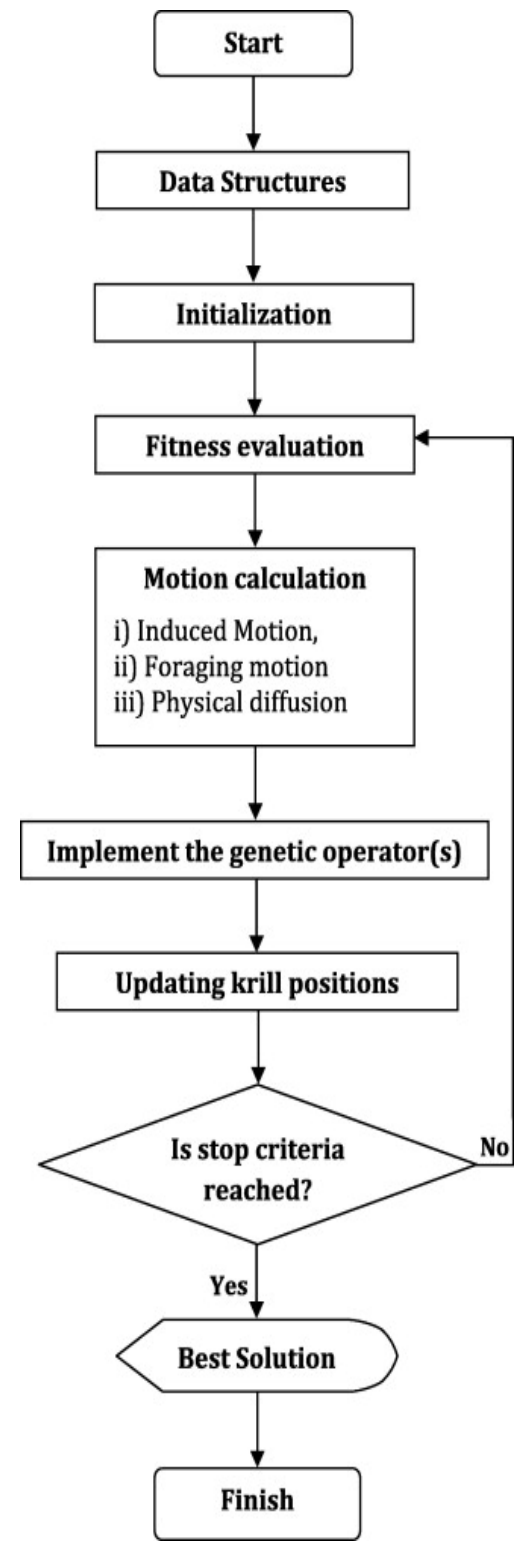

Figure 2. Flowchart for krill herd algorithm

\section{Chaotic Krill Algorithm}

Chaos is a trend that is known as a progress in controlled amplitude which has been happen in a specific vibrant nonlinear system [19]. Intriguing into relation of eminent sensitivity of the chaotic functions in the direction of the most important conditions, broad diversity in this sequence are occurred so that no reappear elements are isolated through the population. In order to generate a logistic chaotic portrait a polynomial quadratic portrait which is mentioned below has been applied:

$y(i+1)=\mu y(i) \cdot(1-y(i)), y(i) o "[0,1]_{,} i=1 \sim n(33)$ 
$y(i)$ in this equation is the magnitude of the $x$ in the " $i$ " th step, and is known control parameter for the system. If $\mu$ is between 3 and 4 it reveal the chaotic behaviour of the function. In this work is $\mu$ assumed to be equal to 4 .

a. Initialization of population.

b. Fitness assessment of each krill individual based on its location.

c. Motion calculation:

Motion induced by the attendance of other individuals,

Foraging movement

Physical propagation

Corporeal propagation pedestal on chaotic sketch

d. Applying the genetic operators

e. Updating krill individual location in the search space.

f. until the stop criteria is reached; Replicate: go to step fitness evaluation

g. End

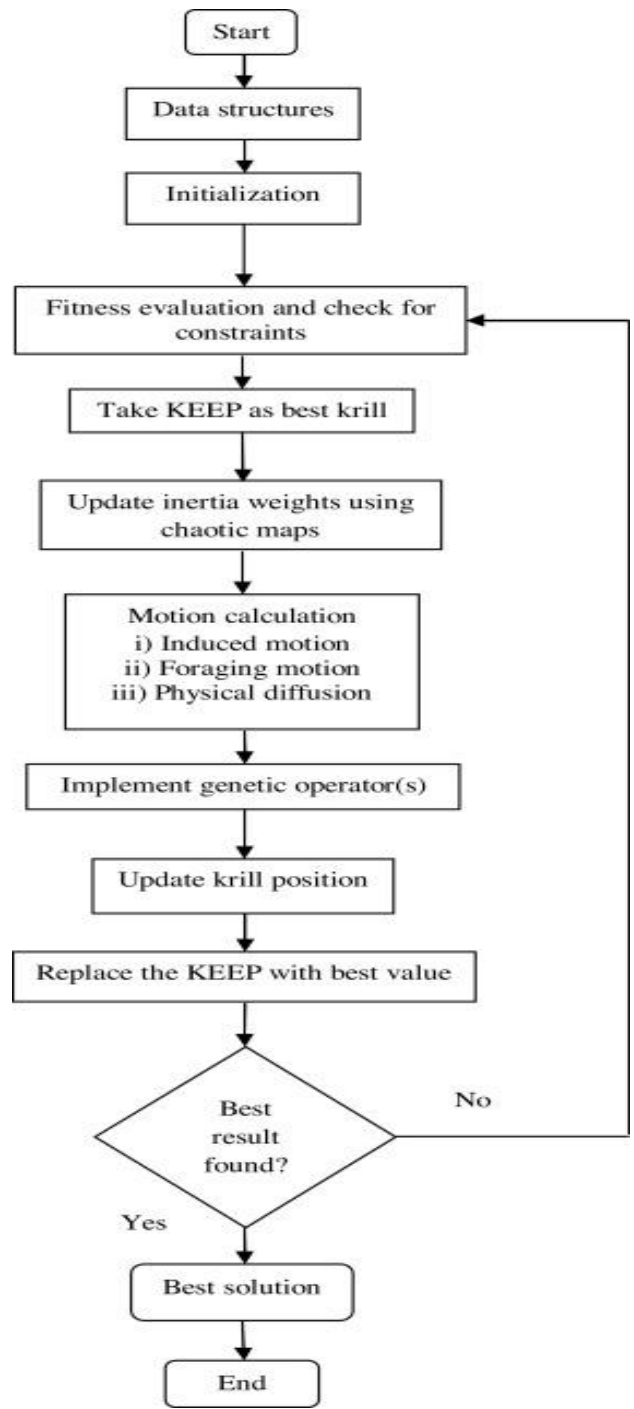

Figure.3. Flow chart for chaotic based krill heard algorithm

\section{Simulation Results}

At first IEEE 57 bus system [20] is used as test system to validate the performance of the proposed Chaotic Krill Herd $(\mathrm{CKH})$ algorithm. Total active and reactive power demands in the system are 1248.23 MW and 334.16 MVAR, respectively. Generator data the system is given in Table 1. The optimum loss comparison is presented in Table 2. Figure 4 gives the comparison of active power loss

Table 1. Generator limits

\begin{tabular}{|l|l|l|l|l|}
\hline $\begin{array}{l}\text { Generator } \\
\text { No }\end{array}$ & $\begin{array}{l}\text { Pgi } \\
\text { minimum }\end{array}$ & $\begin{array}{l}\text { Pgi } \\
\text { maximum }\end{array}$ & $\begin{array}{l}\text { Qgi } \\
\text { minimum }\end{array}$ & $\begin{array}{l}\text { Qgi } \\
\text { maximum }\end{array}$ \\
\hline 1 & 25.00 & 50.00 & 0.00 & 0.00 \\
\hline 2 & 15.00 & 90.00 & -17.00 & 50.00 \\
\hline 3 & 10.00 & 500.00 & -10.00 & 60.00 \\
\hline 4 & 10.00 & 50.00 & -8.00 & 25.00 \\
\hline 5 & 12.00 & 50.00 & -140.00 & 200.00 \\
\hline 6 & 10.00 & 360.00 & -3.00 & 9.00 \\
\hline 7 & 50.00 & 550.00 & -50.00 & 155.00 \\
\hline
\end{tabular}

Table 2. Comparison of Losses

\begin{tabular}{|l|l|l|l|l|l|l|l|l|}
\hline $\begin{array}{l}\text { Para } \\
\text { mete } \\
\mathrm{r}\end{array}$ & $\begin{array}{l}\text { CL } \\
\text { O }\end{array}$ & $\begin{array}{l}\text { DE } \\
{[15]}\end{array}$ & $\begin{array}{l}\text { GS } \\
\text { A } \\
{[15]}\end{array}$ & $\begin{array}{l}\text { OG } \\
\text { SA } \\
{[17}\end{array}$ & $\begin{array}{l}\text { SO } \\
\text { A } \\
{[16]}\end{array}$ & $\begin{array}{l}\text { QO } \\
\text { DE }\end{array}$ & $\begin{array}{l}\text { CS } \\
\text { A }\end{array}$ & $\begin{array}{l}\text { CK } \\
{[21]}\end{array}$ \\
\hline $\begin{array}{l}\text { PLO } \\
\text { SS } \\
\text { (MW }\end{array}$ & 15.5 & 16.7 & 23.4 & 23. & 24.2 & 15.8 & 15.5 & 13.5 \\
) & & & 611 & 43 & 654 & 473 & 149 & 010 \\
\hline
\end{tabular}

\section{Real Power Loss}

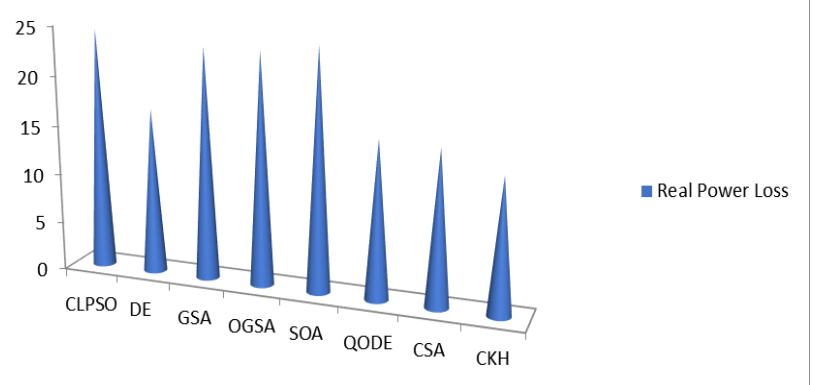

Figure 4. Comparison of active power loss

Secondly IEEE 300 bus system [15] is used as test system to authenticate the performance of the proposed Chaotic Krill Herd (CKH) algorithm. Table 3 shows the comparison of real power loss obtained after optimization. Fig 5 gives the comparison of real power loss

Table 3 Comparison of Real Power Loss

\begin{tabular}{|l|l|l|l|c|}
\hline Parameter & EGA [22] & EEA [22] & CSA [21] & CKH \\
\hline $\begin{array}{l}\text { PLOSS } \\
\text { (MW) }\end{array}$ & 646.2998 & 650.6027 & 635.8942 & 626.0478 \\
\hline
\end{tabular}




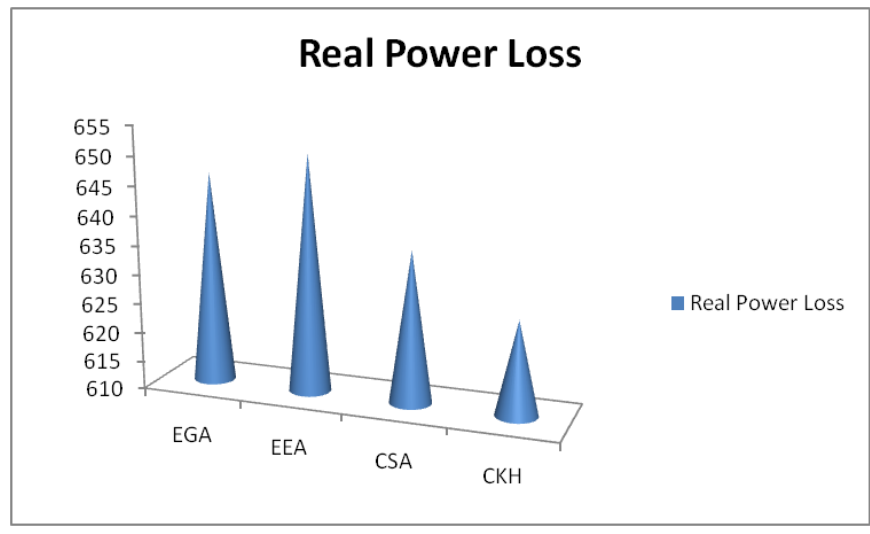

Figure 5. Real power loss comparison

\section{Conclusion}

In this paper Chaotic Krill Herd (CKH) algorithm is successfully solved the optimal reactive power problem. Real Power Loss is reduced considerably when compared to other standard algorithms. Chaos theory and the logistic chaotic mapping are used in substantial propagation to improve the search ability of the proposed algorithm. Proposed Chaotic Krill Herd (CKH) algorithm has been validated in IEEE 57, 300 test systems. Real Power Loss is reduced considerably when compared to other standard algorithms.

\section{References}

1. K. Y. Lee.(1984). "Fuel-cost minimisation for both real and reactive-power dispatches," Proceedings Generation, Transmission and Distribution Conference, vol/issue: 131(3), pp. 85-93.

2. N. I. Deeb.(1998). "An efficient technique for reactive power dispatch using a revised linear programming approach," Electric Power System Research, vol/issue: 15(2), pp. 121-134.

3. M. R. Bjelogrlic, M. S. Calovic, B. S. Babic. (1990). "Application of Newton's optimal power flow in voltage/reactive power control", IEEE Trans Power System, vol. 5, no. 4, pp. 1447-1454.

4. S. Granville.(1994). "Optimal reactive dispatch through interior point methods," IEEE Transactions on Power System, vol/issue: 9(1), pp. 136-146. http://dx.doi.org/10.1109/59.317548

5. N. Grudinin.(1998). "Reactive power optimization using successive quadratic programming method," IEEE Transactions on Power System, vol/issue: 13(4), pp. 1219-1225. http://dx.doi.org/10.1109/59.736232

6. Wei Yan, J. Yu, D. C. Yu , K. Bhattarai.(2006). ”A new optimal reactive power flow model in rectangular form and its solution by predictor corrector primal dual interior point method", IEEE
Trans. Pwr. Syst.,vol.21,no.1,pp.61-67. http://dx.doi.org/10.1109/TPWRS.2005.861978

7. Aparajita Mukherjee, Vivekananda Mukherjee, (2015). "Solution of optimal reactive power dispatch by chaotic krill herd algorithm", IET Gener. Transm. Distrib, , Vol. 9, Issue. 15, pp. 2351-2362.

8. Hu, Z., Wang, X. \& Taylor.(2010). "Stochastic optimal reactive power dispatch: Formulation and solution method". Electr. Power Energy Syst., vol. 32, pp. 615-621. http://dx.doi.org/10.1016/j.ijepes.2009.11.018

9. Mahaletchumi A/P Morgan, Nor Rul Hasma Abdullah, Mohd Herwan Sulaiman,Mahfuzah Mustafa and Rosdiyana Samad.(2016). "MultiObjective Evolutionary Programming (MOEP) Using Mutation Based on Adaptive Mutation Operator (AMO) Applied For Optimal Reactive Power Dispatch", ARPN Journal of Engineering and Applied Sciences, VOL. 11, NO. 14.

10. Pandiarajan, K. \& Babulal, C. K.(2016). “ Fuzzy harmony search algorithm based optimal power flow for power system security enhancement". International Journal Electric Power Energy Syst., vol. 78, pp. 72-79.

11. Mahaletchumi Morgan, Nor Rul Hasma Abdullah, Mohd Herwan Sulaiman, Mahfuzah Mustafa, Rosdiyana Samad.(2016). "Benchmark Studies on Optimal Reactive Power Dispatch (ORPD) Based Multi-objective Evolutionary Programming (MOEP) Using Mutation Based on Adaptive Mutation Adapter (AMO) and Polynomial Mutation Operator (PMO)", Journal of Electrical Systems, 12-1.

12. Rebecca Ng Shin Mei, Mohd Herwan Sulaiman, Zuriani Mustaffa,. (2016). "Ant Lion Optimizer for Optimal Reactive Power Dispatch Solution", Journal of Electrical Systems, "Special Issue AMPE2015", pp. 68-74.

13. Gagliano A., Nocera F. (2017). Analysis of the performances of electric energy storage in residential applications, International Journal of Heat and Technology, Vol. 35, Special Issue 1, pp. S41-S48. DOI: 10.18280/ijht.35Sp0106.

14. Caldera M., Ungaro P., Cammarata G., Puglisi G. (2018). Survey-based analysis of the electrical energy demand in Italian households, Mathematical Modelling of Engineering Problems, Vol. 5, No. 3, pp. 217-224. DOI: 10.18280/mmep.050313

15. M. Basu, "Quasi-oppositional differential evolution for optimal reactive power dispatch", Electrical Power and Energy Systems, vol. 78, pp. 29-40, 2016.

16. C. Dai, et al., "Seeker optimization algorithm for optimal reactive power dispatch", IEEE Trans. Power Systems, vol. 24, no. 3, pp. 1218-1231, 2009.

17. B. Shaw, et al., "Solution of reactive power dispatch of power systems by an opposition-based gravitational search algorithm", International 
Journal of Electrical Power Energy Systems, vol. 55, pp. 29-40, 2014.

18. Gai-gewang,,suash deb,Amir Hossein Gandomi , Amir Hossein Alavi, "Opposition-based krill herd algorithm with Cauchy mutation and position clamping, Journal Neurocomputing, vol.177,Pp 147157,2016, 10.1016/j.neucom.2015.11.018.

19. C.A. Pickover, "Chaos and Fractals: A Computer Graphical Journey", Book ; 1998,ISBN: 9780080528861
20. Available. http://www2.ee.washington.edu/research/pstca/

21. S. Surender Reddy, "Optimal Reactive Power Scheduling Using Cuckoo Search Algorithm", International Journal of Electrical and Computer Engineering , Vol. 7, No. 5, pp. 2349-2356. 2017

22. S.S. Reddy, et al., "Faster evolutionary algorithm based optimal power flow using incremental variables", Electrical Power and Energy Systems, vol. 54, pp. 198-210, 2014 .

\section{Biographical notes}

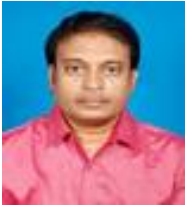

Kanagasabai Lenin has received his B.E., Degree in Electrical and Electronics Engineering from University of Madras, M.E., Degree in Power Systems from Annamalai University and completed $\mathrm{PhD}$ in Electrical Engineering from Jawaharlal Nehru Technological University Hyderabad, India. He published more than 300 international journal research papers and presently working as Professor in Prasad V. Potluri Siddhartha Institute of Technology, Kanuru, Vijayawada, Andhra Pradesh -520007 